\title{
Technologies for obtaining energy from micro-hydropower resources
}

\author{
Cristian Purece ${ }^{1}$, Vasile Pleşca ${ }^{2}$, Lilica Corlan ${ }^{1}$ \\ ${ }^{1}$ Energy Research and Modernization Institute - ICEMENERG, Bucharest, România \\ ${ }^{2}$ University Politehnica of Bucharest, Power Engineering Faculty, Bucharest, România \\ Email: cristianicemenerg@yahoo.com
}

\begin{abstract}
Currently the global demand for electricity and drinking water is constantly increasing. Given its many economic, social and environmental benefits, hydro energy will be an important contributor to the energy mix of the future. Isolated areas, heavily underdeveloped regions, disasteraffected areas have a common need of easy-to-use means to generate electricity. The most efficient way to meet these needs involves the use of various renewable energy resources available locally. One of the main sources of renewable energy is hydro energy, more specifically micro-hydro energy. However, hydropower projects involve various considerations at different levels of project implementation. To make the most of the available hydropower potential, new models of hydraulic turbines were developed. For a cost-effective and efficient hydropower project, the selection of the hydraulic turbine must be optimally studied. The objective of the present work is to carry out a review of the optimum selection mode of the hydraulic turbine that equips a micro hydropower plant (MHP).
\end{abstract}

Keywords. Energy renewable, Small hydropower plant, Hydraulic turbine

\section{Introduction}

The energy from renewable sources is the energy produced from renewable non-fossil sources which, when considered on a human time scale, it naturally recovers. Both the production and the consumption of energy from renewable sources are increasing in EU, but it is necessary to continue the efforts if the objectives of EU regarding the energy from renewable sources are set, namely the growth of this type of energy in the final consumption to reach up to $20 \%$ by 2020 and at least $27 \%$ by 2030 . If EU wants to reduce greenhouse gas emissions to comply with the Paris Agreement on climate change, it is essential to use more energy from renewable sources [1]. Also, increasing the use of energy from renewable sources could reduce the EU's dependence on fossil fuels and energy imports, thus contributing to the security of its energy supply. Moreover, energy from renewable sources can play an important role as a vector of sustainable development in rural areas.

The European Union considers only hydropower plants with installed capacity less than $10 \mathrm{MW}$ as renewable energy sources [2]. Due to its economic, social and environmental benefits, hydropower will be an important factor in the energy mix of the future. Isolated areas, heavily underdeveloped regions, disaster-affected areas have a common need: easily accessible and efficient means of generating energy.

Currently, the main development agencies involved in the supply of electricity in rural areas in many countries recommend the use of micro-hydroelectric plants (MHP) as the most robust and reliable source of electricity generation outside the grid. However, in academic articles, MHP technology is not popular compared to other renewable energy technologies. It is possible to have a contribution for a limited application of water supply, in some countries, outside the hydro graphic network. 
The available data from technical journals regarding MHP, as for wind and solar energy, may have a contribution to extend the level of technology, for the technical and non-technical sides.

This paper provides additional insights into the technology used in MHP and, in particular, the turbines that are used to equip the MHP. This can lead to a better implementation in practice of the technology of conversion of hydraulic energy into electricity for small hydro power.

\section{Micro-hydropower potential}

The water resources due to the inland rivers are estimated at about 42 billion $\mathrm{m}^{3} / \mathrm{year}$, but in unmanaged regime it can only count on about 19 million $\mathrm{m}^{3} /$ year, due to the fluctuations of rivers' flows.

The water resources inside the country are characterized by a great variability, both in space and time. Thus, large and important areas, such as the Romanian Plain, The Moldavian Plateau and Dobrogea, are poor in water. There are also large variations of the flow rates in time, both during a year and from year to year. In the spring months (March-June), it is reached more than $50 \%$ of the annual flowing, reaching the maximum flow rates, which is hundred times higher than the minimum one. All these must compensate the necessity of flow rates with artificial reservoirs.

Regarding the hydropower potential of our country, it is estimated that the theoretical potential of rainfall is about $230 \mathrm{TWh} /$ year, the theoretical [3] potential of drainage water is about $90 \mathrm{TWh} /$ year, and the linear theoretical potential of the water courses is $70 \mathrm{TWh} /$ year. The average theoretical potential of the country's rivers, including the part of Romania from the Danube potential, amounts to $70 \mathrm{TWh} /$ year, of which the applicable technical potential represents $40 \mathrm{TWh} /$ year $(2 / 3$ given by the inland rivers and $1 / 3$ of the Danube).

As wind applications, the technical micro-hydropower potential which can be applicable is less than the theoretical one and in this regard we estimate a value of approx. $1100 \mathrm{MW}$ and a production of $3600 \mathrm{GWh} /$ year.

For MHP economicity depends on:

$\rightarrow$ the location and the related investment (including administrative expenses)

$\rightarrow$ installed power and probable energy production (flow rate, gross head)

$\rightarrow$ distance from the hydro graphic network

$\rightarrow$ maintenance needs (degree of automation, remote operation without personnel, reliability)

$\rightarrow$ the financial conditions and the tariff of the produced energy

Evaluating the applicable economic potential took into account

- Rehabilitation of MHP in operation: $200 \mathrm{MW} / 600 \mathrm{GWh} /$ year

- MHP under construction: $125 \mathrm{MW} / 400 \mathrm{GWh} /$ year

- new MHP (system and autonomous): $75 \mathrm{MW} / 100 \mathrm{GWh} /$ year

In conclusion, regarding the hydropower micropotential (hydro units below $10 \mathrm{MW}$ ) the values are presented in the next table [3].

Table 1. Micro-hydropower potential

\begin{tabular}{|l|c|c|c|}
\hline Parameter & $\mathrm{UM}$ & Technical & Economical \\
\hline Nominal power & $\mathrm{MW}$ & 1100 & 400 \\
\hline Electrical energy & TWh/year & 3,6 & 1,2 \\
\cline { 2 - 4 } & $\begin{array}{c}\text { thousands } \\
\text { TOE/year }\end{array}$ & 310 & 103 \\
\hline
\end{tabular}

At the beginning of 2018, there were 118 economic operators that had 317 small hydropower plants production capacities (below $10 \mathrm{MW}$ ) - SHPP and micro hydropower plants - MHP. These small hydropower have together an installed power of $341.6 \mathrm{MW}$, which represents about $5 \%$ of the total installed capacity on hydro. The production realized in 2017 by these SHPP and MHP which are 
privately owned was approx. $493611 \mathrm{MWh}$, which represents about 3\% of hydro power production [4].

\section{Hydropower schemes used in the case of micro-hydropower plants}

There are, generally, two main ways to develop a micro-hydropower plant [5], namely:

$$
>\quad \text { hydropower sites with accumulation (dam hydro) and }
$$

\section{Hydropower sites with accumulation}

For micro-hydropower plants, generally, it is not feasible, economically speaking, to create new accumulation, except only isolated locations where the energy value is very high. The storage for a micro-hydropower plant is generally limited to small volumes of water from a new or existing accumulation. The term used to describe small volumes of water deposits is polder or compensatory basin.

Polders (compensatory basins) can bring benefits to micro-hydropower plants by increasing energy production and/or by increasing revenues. Unfortunately, the investment required to achieve such a scheme is much higher than the one corresponding to a micro-hydropower plant on the river line, compared to the increase in revenues, and therefore, these schemes are not economically feasible.

Schematically, a hydropower sites with accumulation is shown in figure 1 . The figure highlights the main works of such a hydropower site: the dam that forms an upstream accumulation, the penstock to the micro-hydropower plant, an penstock which is in fact a forced pipeline because the flow takes place under pressure, the building of the micro-hydroelectric plant that houses the hydraulic and electrical equipment necessary for operation, transmission lines for electric current outside the power plant and tailrace.

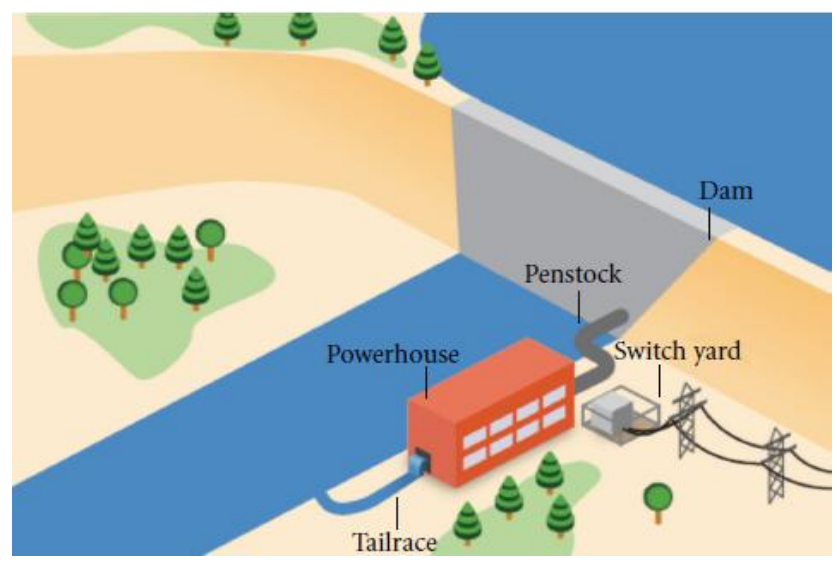

Fig. 1. Hydropower site with accumulation for MHP [6]

Hydropower site on run of river

The hydropower sites on run of river line refer to the operating mode in which the hydropower plant uses only the available water from the natural flow of the river. Hydropower sites on run of river suggest that there is no water accumulation or flooding, and the power fluctuates with the flow rate of the river.

The power produced by the micro-hydropower plants on run of river fluctuates with the hydrological cycles, so they are more suitable to give energy in a larger electrical system. Individually, they generally do not provide much secure capacity. Therefore, isolated communities that use microhydropower plants often need additional power from another power source. A micro-hydropower plant on run of river can cover all the electricity needs of an isolated community or industry if the minimum flow rate of the river is sufficient to meet the requirements of the required peak of electricity.

MHP "run of river" may imply the need of diversion of the river path. The diversion is often necessary to exploit the benefits of a better head. In general, the diversion projects lead to a reduction of the river flow rate between the intake and the hydropower plant itself. Usually, a spillway is required to diversion the flow rate to the intake. 
Perhaps the most suggestive scheme for micro-hydro power plants "run of river" is the one shown in Figure 2, in which the scheme is that of a dam-type plant, to which the hydropower plant is part of the dam front.

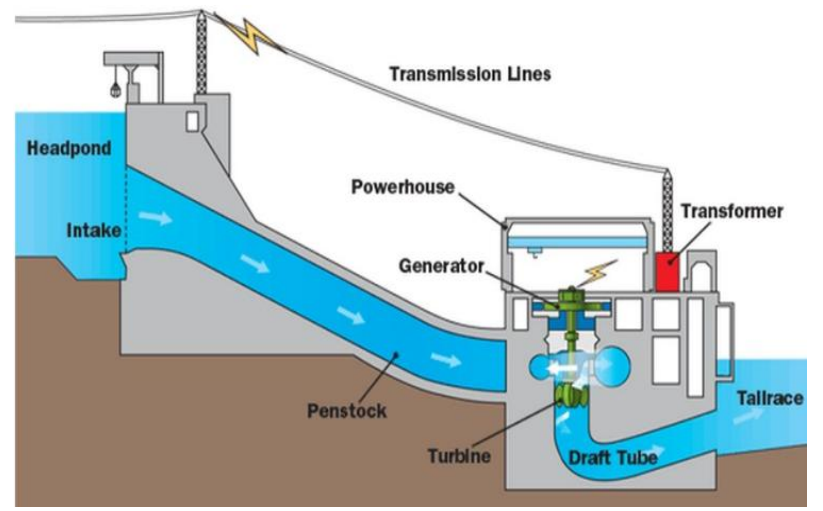

Fig. 2. Hydropower sites "run of river" in which the hydropower plant is part of the dam front [5]

Other schematizations for the MHP "run of river" may be those presented in Figure 3. Figure 3 shows a MHC on run of river, in which there is a spillway that only serves to diversion a flow rate from the main course, a share of the river's flow rate, and it's driving through a penstock that follows the water path to the MHP building where water energy is extracted in turbines. The water is then returned to the natural course.

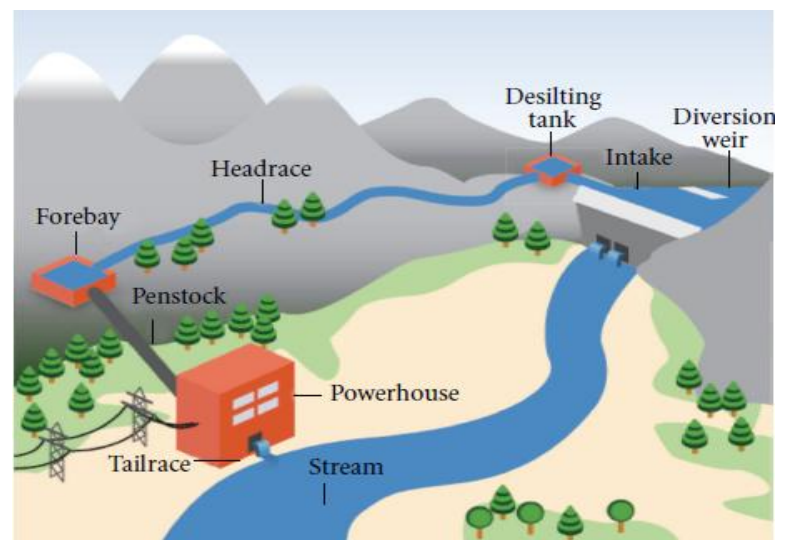

Fig. 3. Hydropower sites "run of river" with long diversion [6]

\section{Types of hydraulic turbines}

Several types of hydraulic turbines are used for MHP equipment. Hydraulic turbines can be divided into two broad categories: action or impulse turbines and reaction turbine [8]

Impulse turbines

- The Pelton turbine consists of a wheel on which several buckets are fixed, while a high speed jet acts tangentially on the wheel. The jet hits each bucket and it is divided into two, so that each half is reflected at almost $180^{\circ}$. Almost all the energy of the water is used to impact the buckets, and the reflected water is collected in a canal.

- The Turgo turbine is similar to Pelton, but the jet hits the runner at an angle of 20 degrees, so water enters one side of the runner and exits the other side. Therefore the flow rate is not limited by the amount of discharged water (as in the case of the Peloton turbine). As a result, the Turgot turbine may have a smaller diameter than the Peloton turbine, for the same output power.

- The Bánki turbine consists of two thick sheet disks on which some blades are welded. The water jet enters through the upper part of the runner between the curved blades, and exits through the opposite side, thus passing a second time through the blades. The blades are shaped so that at each passage 
through the periphery of the runner the water transfers a part of its energy, before falling, with little residual energy.

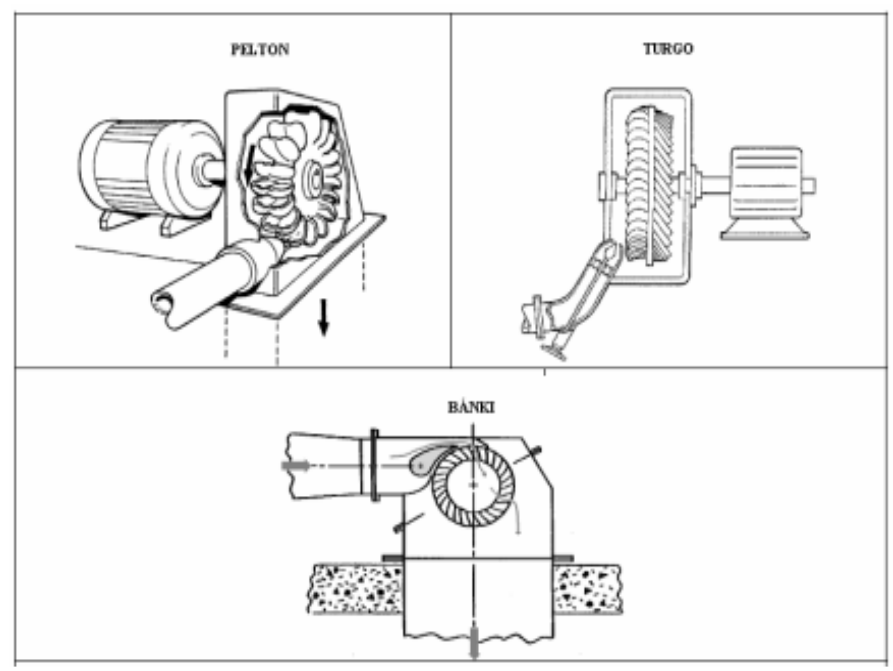

Fig. 4. Types of impulse turbines [7]

\section{Reaction turbine}

Reaction turbines use flow rate entering the runner to generate hydrodynamic forces acting on the runner blades by putting them in motion. They are distinguished from the action turbines by the fact that the runner always operates in a casing completely filled with water.

All reaction turbines have a diffuser, known as a "draft tube", under the runner through which the water is drained. The "draft tube " slows down the drained water and reduces static pressure in the area under the runner, thus increasing the net head.

Propeller turbines are, in principle, similar to the propellers of a ship, but operating in the opposite direction.

The main reaction turbines are Kaplan, Francis, Ellice, Propeller turbines, helically with S hydraulic circuit.

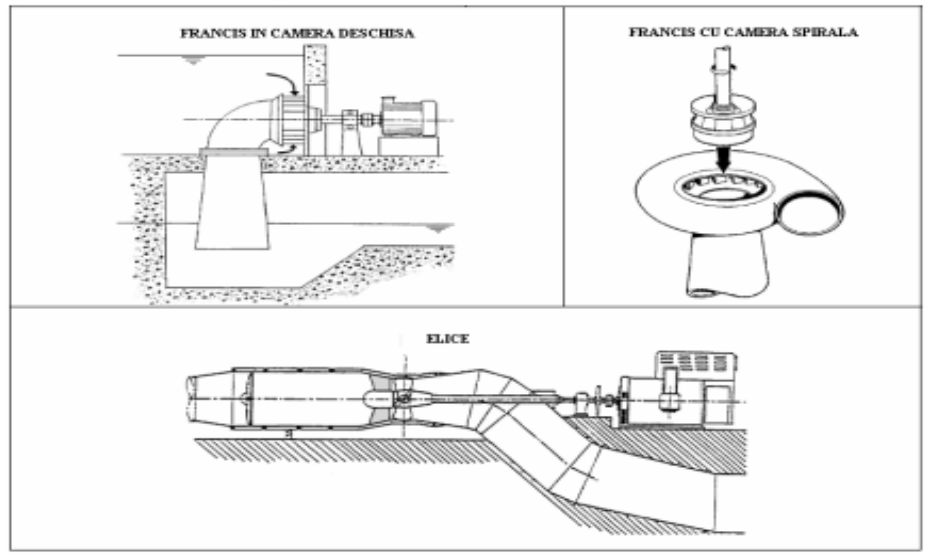

Fig. 5. Types of reaction turbines [7]

New types of hydraulic turbines

A relatively recent invention is the very low head VLH (Very Low Head - Figure.6), able to use heads from 1 to $3 \mathrm{~m}$, not sealed under pressure housing and which requires extremely simple construction work. The major disadvantage of this type of turbine is the sensitivity to frost. 


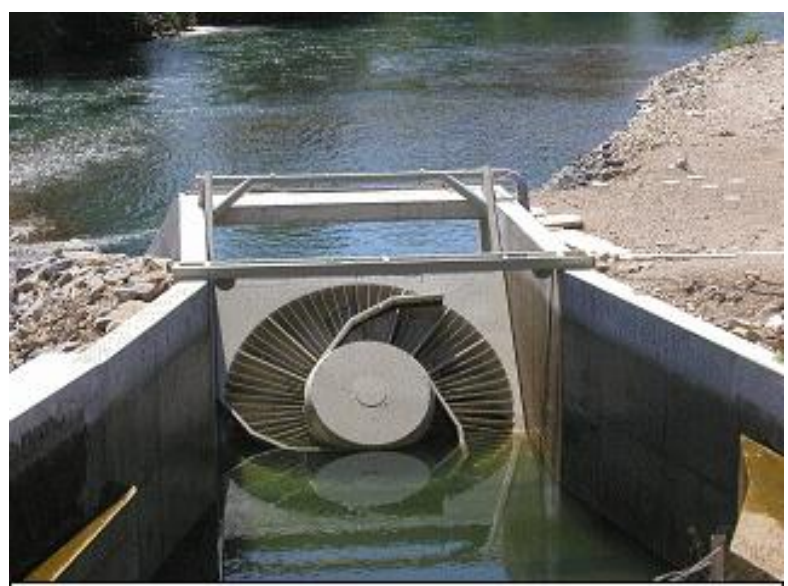

Fig. 6. Very low head turbine from Troussy (upstream view) [8]

Archimedes' screw has been used since ancient times for water transfer to a higher level (irrigation of the Hanging Gardens in Babylon). In recent years the device has also been used for the production of electrical energy. The Archimedes' Screw turbine or Fish Friendly turbine (the screw was also used to move fishes from one lake to another).

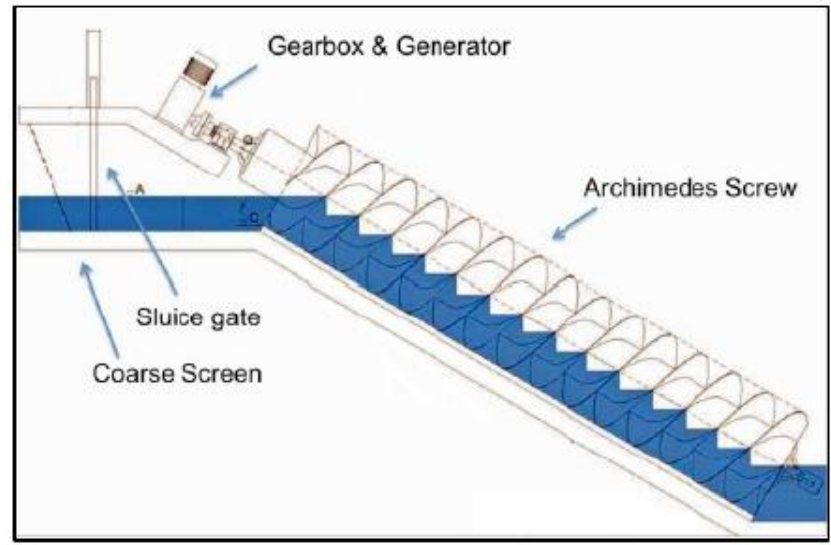

Fig. 7. Archimedes' Screw Turbine [9]

\section{Selection of hydraulic turbine}

The selection of the hydraulic turbine, the geometry and the dimensions of the turbine depend mainly on the head, the flow rate and the runner speed. Figure 8 shows the working range of different turbine types as a function of net head $\left(\mathrm{H}_{\mathrm{n}}\right)$ and installed flow rate $(\mathrm{Q})$.

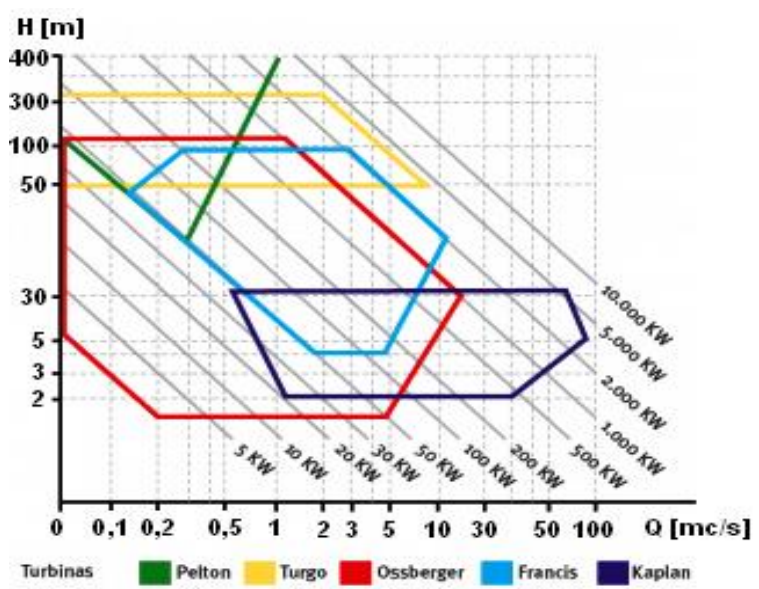

Fig. 8. Turbine selection nomogram for equipping a micro-hydropower plant [5] 
The nominal flow and net head $\left(\mathrm{H}_{\mathrm{n}}\right)$ determine the set of turbine types applicable to the hydropower site and the flow environment. The corresponding turbines are those for which the flow rate and head are included in the operating ranges. A point defined according to the above is generally represented in several similar ranges. All those turbines are suitable, so it will be necessary to calculate the installed power and energy production in relation to the costs, before taking a decision. Due to the fact that a turbine can only operate in a certain range of flow rates (between the maximum value and, practically, the minimum applicable), it may be advantageous to install more turbines with lower installed flow rate instead of a higher capacity one.

Also, in order to determine the optimal type of turbine in equipping a MHP, in addition to the hydraulic head loss, it is necessary to know the monthly average flow rate determined for a period of decades [10].

Given the complexity of designing a new turbine for a particular location and application, the initial selection of turbine technology should be based not only on technical, but also social, environmental and economic factors in a conventional manner. However, turbines are currently selected mainly based on their specific speed $\left(n_{s}\right)$. The specific speed of the turbine is calculated with relation (1).

$$
n_{s}=\frac{n \times \sqrt{P \times 1.356}}{H^{5 / 4}}
$$

where:

$\mathrm{n}_{\mathrm{s}}$ is the specific speed in [r.p.m]

$\mathrm{n}$ - nominal rotation speed of the turbine [r.p.m]

$\mathrm{P}$ - the power at turbine torque in $[\mathrm{kW}]$

$\mathrm{H}$ - the nominal head of the turbine in [m]

Once the specific speed $\left(n_{s}\right)$ is determined, the graph shown in Figure 9 can be used to determine the type of turbine that can be used for a particular micro-hydropower plant.

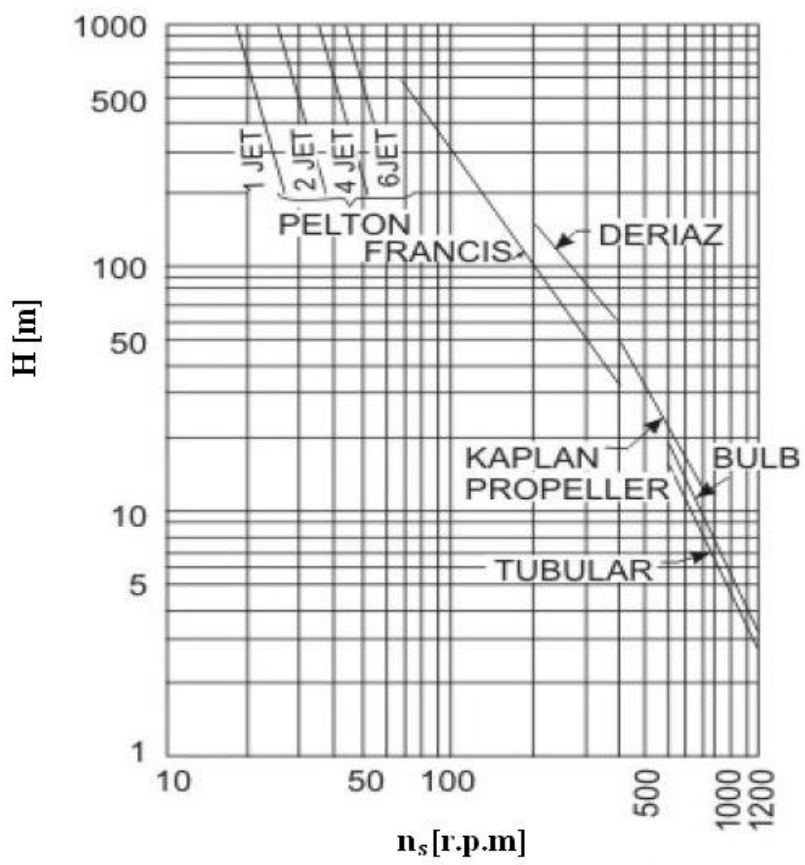

Fig. 9. Graph for the selection of the turbine according to the specific speed [7] 
Although this option restricts the possibility of adopting the most used types of turbine, it does not refer to the qualitative factors necessary for the successful and sustainable long-term adoption of the resulting system.

In the preliminary selection of the type of turbine used for a small hydropower project, the multicriteria analysis proposed by Williamson, Stark \& Booker can be applied [11].

The factors used for the selection of the technology, of the type of turbine used for a small hydropower project can be extended beside those used by Williamson and collaborators as follows:

- Constructability assessment - the degree of complexity for the construction of components and the assembly of the MHP. This involves the necessary materials, the equipment and labor force used, as well as the tolerances allowed during the hydropower development.

- Cost - the monetary cost required for hydropower development

- Maintenance and service capacity - the level of repair and continuous maintenance, necessary for the hydropower site to function properly but, also, the complexity of the maintenance process

- Portability - the volume of construction and transport required to be managed. The hydropower sites will be located near the rivers and usually involve inclined lands located in rural areas where road infrastructure is almost non-existent

- Modularity - the ability to disassemble the general system into smaller components to allow the in situ replacement of parts and to fix the defects that have occurred

- Efficiency - efficiency in accordance with the design conditions and outside the design conditions

\section{Another important parameter in the choice of turbine is the efficiency of the turbine}

The turbine efficiency $\left(\eta_{T}\right)$ is defined as the ratio between the power supplied by the turbine (the mechanical power transmitted to the turbine shaft) and the absorbed power (the hydraulic power equivalent to the measured rate flow corresponding to the net head). In order to estimate the overall efficiency, the turbine efficiency must be multiplied by the generator efficiency $\left(\eta_{\mathrm{G}}\right)$. A turbine is designed to operate as close to its maximum efficiency point, usually at $80 \%$ of the maximum flow rate $\left(\mathrm{Q}_{\max }\right)$, and as the flow rate departs from this point, the efficiency of the hydraulic turbine decreases [12].

Also from analyzing the performance measurements made by ICEMENERG [13], it can be seen that at the nominal power of the EOS 500 turbine the maximum efficiency was $66 \div 68 \%$, and for EOS 1100 the maximum efficiency was $74 \div 78 \%$. When operating at partial loads, the overall efficiency $(\eta$ $\left.=\eta_{\mathrm{G}} \times \eta_{\mathrm{T}}\right)$ decreases rapidly, as can be seen from Figure 10 .

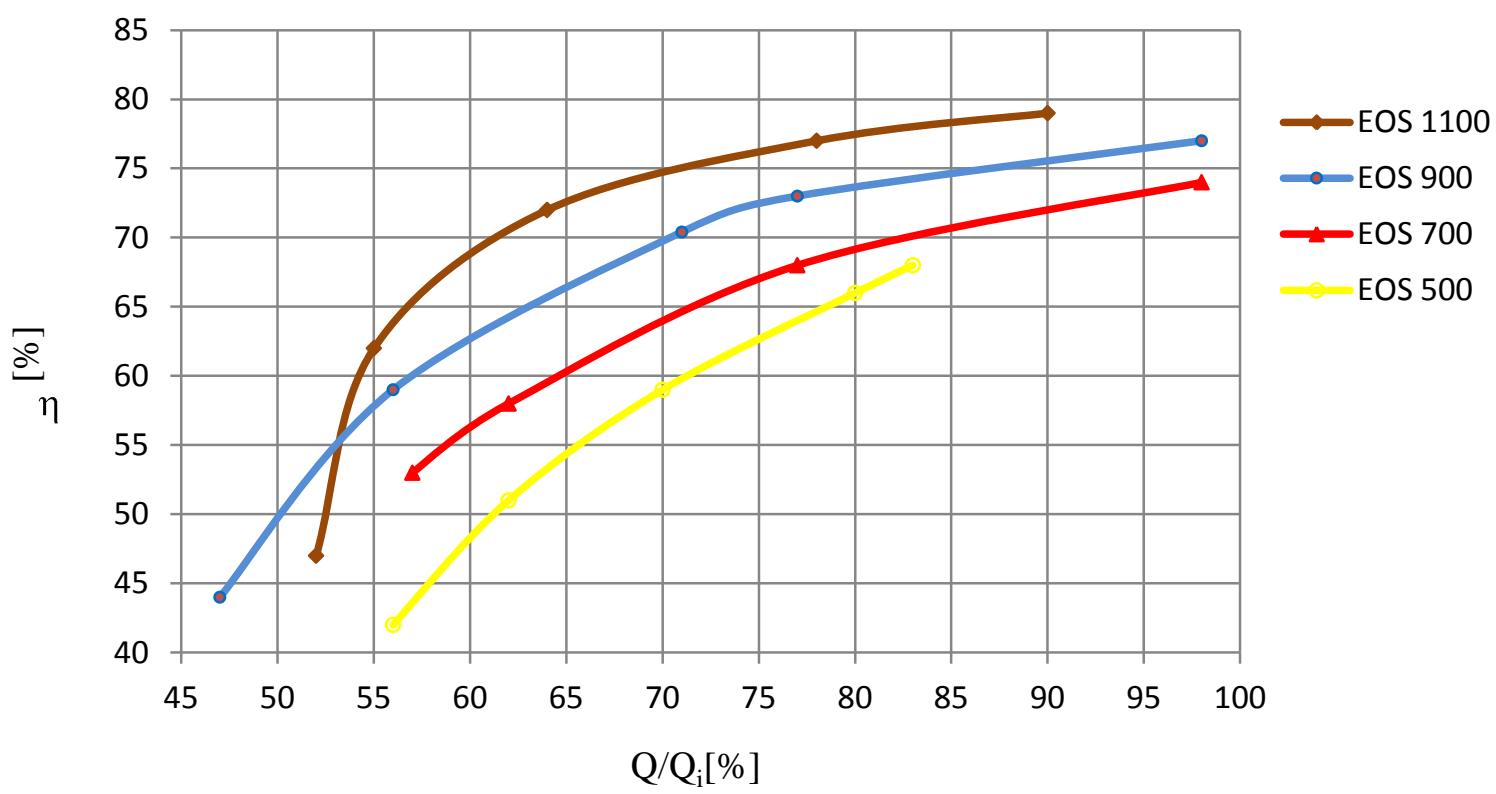

Fig. 10. Overall efficiency of the small hydro power plant for various turbines by type EOS 
Overall efficiency is expressed through the relationship (2).

$$
\eta=\frac{102 \times P_{G}}{Q \times H_{n}}
$$

And in Figure 11 is presented the overall efficiency in function by power of generator $\left(\mathrm{P}_{\mathrm{G}}\right)$ for hydro unit no. 2 from MHP Dej Monastery

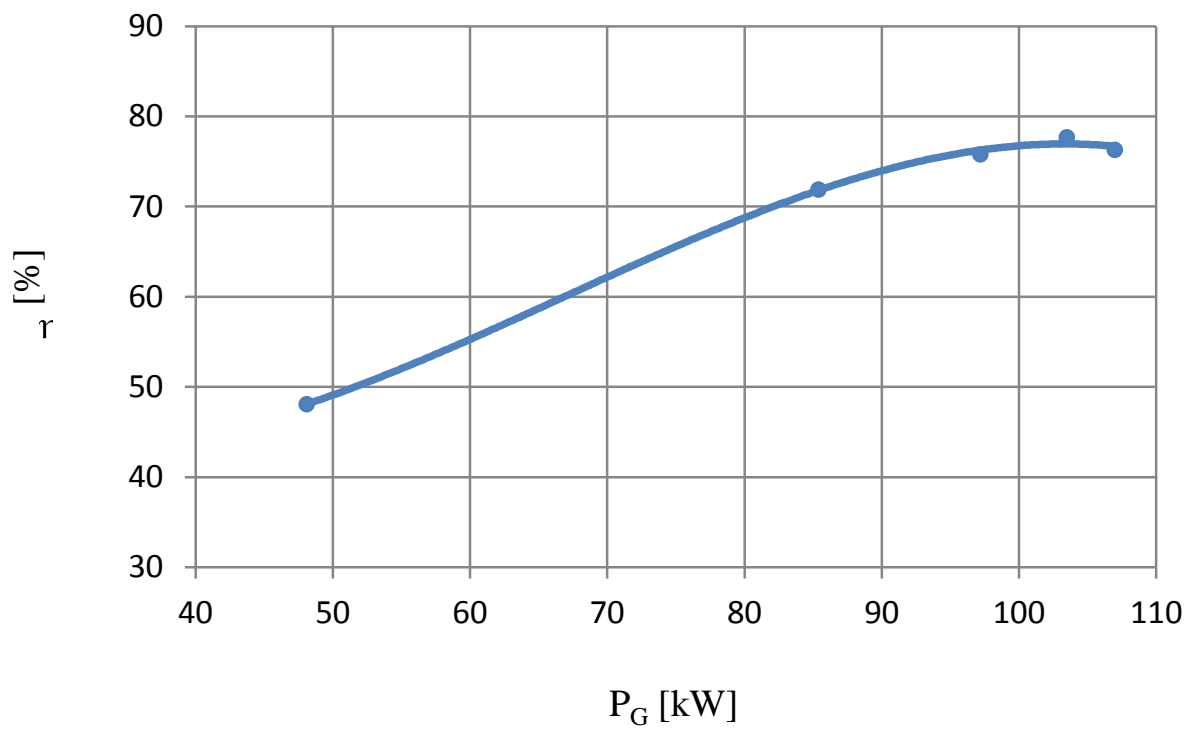

Fig. 11. Variation of overall efficiency as a function of power at hydro unit no. 2 of the MHP Dej Monastery

It can be seen in Figure 11 the overall efficiency of $78 \%$ has a maximum value for the net head $\left(\mathrm{H}_{\mathrm{n}}\right)$ $4.43 \mathrm{~m}$ and $103.5 \mathrm{~kW}$ power generator.

\section{Conclusions}

This paper examines from a technical point of view, the optimal way of selecting a hydraulic turbine in the case of small hydropower projects. The selection of the hydraulic turbine is the first phase of a project that considers the development of a micro-hydropower plant and its connection to the network. The present work can be considered a guide for the developers in selecting the hydraulic turbine according to the operating conditions that are available.

The final choice, between the use of one or more hydro units, or between one type or another of turbine, is the result of an iterative calculation that takes into account the hydropower factors and parameters presented in chapter 5, but also the investment costs and the annual production of electricity.

The projects for the realization of a MHP are cost-effective for a sale price of electricity between 20 Euro/MWh and 36.6 Euro/MWh. The feasibility of MHP projects is improved due to the mechanisms of promoting SRE projects through valorisation of green certificates at a price between 24 and 42 Euro per green certificate according to government decision 968/2005. The revenues obtained from trading the $\mathrm{CO}_{2}$ emissions law improve the efficiency of the this projects type.

\section{References}

[1] Vatau R., Toma M., Mico-hydro power plants: tradition and perspective, Energetica, ISSN 14532360, no.11, November 2005

[2] Popoviciu O. M., Bordeasu I., The need to harness the hydropower potential in Romania, AGIR Bulletin no. 3, September 2007 
[3] Popa F., Paraschivescu A., Popa B., The hydropower potential of Romania, Published in Vol. of the $4^{\text {th }}$ Conference of Hydropower in Romania DORIN PAVEL, 26-27 May 2006, Ed. Printech, Bucharest

[4] Arpad K., Micro-hydro power plants and the environment. Effects analysis and best practices, Guide developed in December 2012 under the WWF-DCP 9E0793.01 contract

[5] Popa B. Hydropower Course. Micro-hydro power, Polytechnic University of Bucharest, Faculty of Energy 2014

[6] Intergovernmental Panel on Climate Change, Special report on renewable energy sources and climate change mitigation, chapter 5: hydropower, Special Report of IPCC, Cambridge University Printing Press, 2012.

[7] Sangal S., Garg A., Kumar D., Review of Optimal Selection of Turbines for Hydroelectric Projects, International Journal of Emerging Technology and Advanced Engineering Volume 3, Issue 3, March 2013

[8] https://www.power-technology.com/features/feature115301/

[9] https://www.hallidayshydropower.com/hydro_about.php

[10] Driscoll H.J.R., Micro-hydro power in Dorset: A re-assessment of potential installed capacity, Earth \& Environment, University of Leeds Press, 2008, p. 114

[11] Williamson, S. J., Stark, B. H., \& Booker, J. D., Low head pico hydro turbine selection using a multi-criteria analysis. World, Renewable Energy Congress, Linkoping, Sweden, 2011

[12] Badea A., Necula H. et al., Renewable energy sources, Ed. AGIR, ISBN 978-973-720-469-1, Bucharest 2014

[13] *** Verification of the performances of the EOS type hydro unit from MHP Dej Monastery, Study elaborated by ICEMENER, Bucharest 1995 